Nair, P. \& Sharma, N. (2014). Connect Exchange Programs: A Critical Component in Media Studies for Indian Media Schools. Journal of Educational Technology Development and Exchange, 7(1), 33-48.

\title{
Connect Exchange Programs: A Critical Component in Media Studies for Indian Media Schools
}

\author{
Pradeep Nair, \\ Central University of Himachal Pradesh \\ Navneet Sharma \\ Central University of Himachal Pradesh
}

\begin{abstract}
This article addresses the objectives, philosophy, and need assessment of connect exchange programmes (CEP) in media studies. It underlines the importance of CEPs as an effort to mitigate the chasms created by a discriminatory, hierarchical, and fragmented society. Simultaneously, this article questions how CEPs can contribute to the paradigm of media studies when the institutions of media and media Studies still abide by the vision of age-old understanding of the constitution of Media and its function. This article raises a pitch for viewing media studies as a discipline with an integral commitment to society and social issues rather than relying upon the training of 'graduates' to fit in the needs and demands of the job market. This article emphasizes that how a CEP can contribute to the making of a 'universal global citizenry.'
\end{abstract}

Keywords: Connect Exchange Program, Pedagogical Endurance, Media Studies, Globalization, Collaboration

\section{Introduction}

Indian universities and institutions, both at state and central level, have been collaborating with distant universities and institutions outside the country over the past few years to develop greater mutual understanding through faculty exchange, evolving methods to expedite educational reforms through collaborative teaching, fostering economic development through graduate student exchange programs to negotiate global society, and is taking all the efforts to engage civil society through making connections between the academia, the community, and the work place (Haythornthwaite \& Wellman, 1998). As far as media studies are concerned, a conceptual framework is required to design and implement a connect exchange program to enhance students and faculty exchange and to reform the technical and humanities-based Indian media educational systems for a global media focus.

A connect exchange program (CEP) is critical to refine the existing academic and co-curricular media programs of Indian universities to include more about globalization (Bhaduri, 2008). Nearly all of the newly established Central universities are 
developing and offering post-graduate and undergraduate programs in communication studies to maximize the University Grants Commission (UGC) and Ministry of Human Resource Development (MHRD) resources. Older state and central universities are also now redefining their existing media programs in terms of global new media technologies. All this requires new professional development and orientation opportunities to the faculties of these universities, and thus, urging these universities to think and act globally.

\section{The Situational Context for CEPs}

Over the last two decades, since the New Economic order implemented in 1991, India has remarkably taken strides in the domain of higher education. It has expanded at a fast pace. The initial ground for quantitative expanse is all set and this is the right time when issues and concerns for quality should be prioritized (Agarwal, 2009). Moreover, opening up Indian market and social spaces for global and intercultural melee has put forth different kinds of quality needs and constraints to higher education in India. Higher education, being the tertiary level of institutional schooling, is the last resort for evolving a global citizenry (Altbach, 2004). At this level of education only one is equipped to appreciate the nuances and can celebrate the differences already marred by the conflicts arising out of region, religion, class, colour, language, sex, and sexuality. It is at the very onset of any higher education program of any country, howsoever fundamentalist it may be, that it would evolve 'Universal' residents of the globe. This might be the probable reason why tertiary level education is imparted by the institutions known as 'University' (Tejerina, 2011). The connect exchange program (CEP) is another effort to achieve this objective. Simultaneously, in evolving 'knowledgesociety' world the knowledge 'construction' process would be a collective effort. This would also reduce the scepticism towards others' knowledge. The co-construction of knowledge is the most effective way to resolve the fanatic orientation to one's identity concern emerging out of discriminatory systems.

The technological improvements and innovations have brought forth a radical shift in the speed of human and information circulation. In this era, one encounters the other individual, civilization, and culture every other moment (Allen, Bonous, \& Teranishi, 2006). Media for the purpose of information circulation has already transgressed its boundaries in making an impact and in influencing the 'culture.' Media studies have emerged as a discipline and discourse to map this, and a CEP in media studies has become a necessity which anyone can hardly be of sceptic.

\section{Review of Literature}

The CEPs in media studies aims at developing technological literacy resources, networks and data storage capacities, and multi-ethnic and multicultural inclusion and awareness to strengthen the resources to offer the media programmes with an international requisite. The operational approach is to engage the students and faculty of collaborating institutions in tasks involving multicultural multiplicity (Celly, 2008).

The CEP in media studies helps one to understand and appreciate the varied cultural and institutional practices and praxis of the media functioning with a precept for a global synchronization. The purpose of these programs is to educate and prepare a skilled workforce for global media business. It is an extension of research, faculty, and resource support to media institutions of both developing and developed world to reach 
people beyond geographical boundaries, time, and space (Coverdale, 2013).

The curricula of media courses offered by mass communication and journalism departments of Indian universities are many times out of sync and not relevant because these institutions abide by the vision of what constitutes media and its functioning of ageold paradigms. The structure and content of media programs offered by Indian universities are mostly focused on conventional classroom teaching and some practicum in the media production laboratories. The new interactive media tools such as mobile phones, blogs, twitter, and other Internet and mobile mediated applications are least utilized. The emerging vistas and avenues like digital advertising, corporate communications, influence, lobbying, media economics, visual communication, etc. are either neglected or discussed in a passing mention. The emphasis of media education is still largely on the 'deconstruction of texts' in press, television, and cinema. The need is to shift from domestic to multinational media conglomerates that are shaping the form and substance of practices and texts of multifarious media industries (Anderson, 2003).

A CEP can help the media institutions integrate highly interactive learning environments through onsite, online, and mobile modalities to simulate ground-breaking thinking, research, and policy work in media and communication studies. In present times, content flows across multiple media platforms and is combining technological, industrial, cultural, and social changes (Ghosh, 2008). An exchange program can help the participants closely observe and learn new development in communication and media business/practices with a critical approach and further help in learning how to practice these in different practical and pragmatic situations by using latest media tools.

\subsection{Pedagogical Endurance of CEPS}

There is a great diversity in media in terms of content, technology, styles of message construction, delivery, and in the audiences that can be reached. This has opened up opportunities for people to 'narrate' with a different perspective over multiple media platforms. According to Dahlgren (2009), the new media content development and instructional design requires 'reflective practitioners' with the ability to deliver a wide range of information according to the interest and demand of the clientele. Both domestic and global media want professionals who can 'fit and adjust' in their organizational framework and could meet the demands of the market as efficiently as possible (Dahlgren, 2009). Market is ready only for 'efficient communicators' who can tell a quick story to the audience in the simplest and most attractive way possible, but can also create a story where there is none.

In this context, a CEP in media studies can help the participating institutions develop, update, and revise content, pedagogy, and assessment systems that support experimental, interactive, and student-centred learning. It could help revamp the existing structure of teaching communication, and media courses in media institutions to cater to the diverse choices and learning styles of the students. The program can educate the media faculty in being good facilitators who shall facilitate the students to learn with activities and engagement. A CEP in media studies can help develop a pool of reflective and thoughtful learners that can be useful in effective and customized learning. The program can also help institutions of media studies collaborate to produce graduates in media with an independent and critical skill. A CEP in media studies with a focused academic instruction would scaffold extended intercultural professional relationships. It 
could further provide practical pedagogical approaches for workplace problem-solving to increase innovation capability and media entrepreneurship in the country (Messer \& Wolter, 2005).

The pedagogical strength of CEP in media studies lies in its approach to develop conceptualization, critical thinking, and problem-solving skills. These kinds of programs provide multifaceted exposure across a variety of topics related to political, social, economic, and cultural aspects of media process. In this digital era, the communication technologies strategized for connect exchange program help the collaborating institutions deepen connections and ideas through integrating digital media tools (Hasan \& Nussbaum, 2012). It further helps create a device-agnostic digitized content and pedagogy. Experiments like connecting the classrooms of collaborative institutions through a Multiprotocol Label Switching (MPLS) based data network deployed by Birla Institute of Technology and Sciences can provide access to key content exchanged at any location and time. A facility like this can help the students of the participant institutions in an exchange program interact with the experts during guest lectures, virtual workshops, and other academic pursuits in real-time.

In CEP, media education institutions from India and abroad can mentor other institutions to help them develop research capabilities, framework, policies, and practices. The exchange can further expand in the form of a joint research program and other research collaborations across themes that are of mutual interest (Davies, Devlin, \& Tight, 2010). Recently, Anwar Jamal Kidwai Mass Communication Research Centre (AJKMCRC) of Jamia Millia Islamia University of India has collaborated with the University of Westminster, London to offer 'practice' based $\mathrm{PhD}$ program in Film and Production Studies. The JMI University, New Delhi has also collaborated with York University, Canada for exchange of faculty and students. For improving the quality of media courses in higher education institutions, a CEP can also help conduct faculty development programs where the faculty members of media institutions in a region/country can participate. The reach of the program could be extended through virtual platforms across geographic boundaries (Hasan \& Nussbaum, 2012).

\subsection{The Present Condition of Media Studies Curricula in India}

There are twenty-five departments of mass communication and journalism from the surveyed 32 central universities in India that are offering post-graduate, undergraduate, and diploma programs in areas ranging from journalism and mass communication to cultural studies, media studies, media production and management, health communication, etc. Around 100 state universities are also offering courses in journalism and mass communication. The courses offered by these central and state universities are bereft of theoretical groundings. Some of the courses in media studies offered even by institutions like AJKMCRC of Jamia Millia Islamia University, Indian Institute of Mass Communication (IIMC) and Film, and Television Institute of India (FTII) emphasize more on 'technical training' in audio-video production. The courses offered by these above mentioned institutions are 'practice' dominated. On the other side, the media courses offered by Tata Institute of Social Sciences (TISS) are inclined towards cultural studies whereas Mudra Institute of Communication, Ahmedabad (MICA) focuses more on the management part of media business. 
The structure of courses offered by the other state and central universities have some variation, but most of them have a presumed certain level of understanding of politics, culture, society and social process, and a basic linguistic competence (Maslog, 1990). This is more evident in those media programs where the focus is on 'journalism,' while those focusing on commercial media have stressed a little less on language ability. The entrance examination to the most of programs is structured around general knowledge, current affairs, some familiarity with media, and writing ability. The curriculum has a focus on processes in society, economics, politics, and culture, as well as honing the basic skills in creative expression and overlying this with technological skills. Most of the conventional Communication and Journalism programs offered by the state universities confine themselves to academic criticism, with no pretence of offering a 'job-oriented' practical course (Lavender, Tufte, \& Lemish, 2003). In the last decade, the general abilities and knowledge level of students entering communication courses have changed due to Internet and social media, but most of the communication courses have not yet accommodated these changes in their curriculum.

Similarly, the scope of media studies has also expanded from the conventional sub-disciplines of Journalism, Advertising, Public Relations, and Television and Radio Production to a whole range of other social communication fields such as Health and Environment, Advocacy, Social Media, Technical Writing, Editing, Multimedia, Animation, Gaming, Music, Content Development for mobile phones, Web Journalism, and many other niche areas that are emerging, identified by technology and by content (Downing, 2004). The constant advancement in communication technologies has increased the human involvement in its access. Further, the rapid, almost daily changes in media technology and the resulting effects on society and culture make the field of media studies one of the most dynamic and exciting areas to study. Existing media programs being offered by the Indian universities are trying to deal with these new developments and demands, but to a certain extent only.

The Central Universities newly established in 2009, which are offering Mass Communication courses like Himachal Pradesh, Tamil Nadu, Jammu, Rajasthan, and Kashmir are incorporating more contemporary media structures and approaches in their innovative curriculum and pedagogy. These universities are procuring advance media production equipment and making their syllabi more applied with a focus upon new media technologies.

In short, the whole approach to the teaching of media studies in India needs a radical re-thinking and revamp. Newer strategies need to evolve so that a critical interpretation of the conventional and new media, both as technologies and as a source of information and media content, can become a part of media education (Levy \& Gurevitch, 1994). The program needs to be redesigned and updated to engage the students in a theoretical and methodological understanding of the social and psychological impact of evolving media applications like social networking, digital broadcasting, and how they are practiced for socially constructive purposes. CEP can help institutions of media studies of this country to design and offer industry-oriented courses with a focus on critical thinking by collaborating with premier media institutions around the world in interdisciplinary areas of scholarship and research. Joint practicebased research projects with the collaboration 
of premier institutions will help the Indian institutions of media studies develop a critical and practical knowledge of how audiences interact with the media and how media influences human behaviour, choices, and decision making abilities.

\subsection{CEP as a Critical Component}

A CEP in the education and training of the media and communication courses can help maximize mutual learning between media institutions of both countries in engagement. This would extend support to learn and accommodate the recent developments taking place in media industries at national, multinational, and transnational level in their syllabi, curriculum, and pedagogical practices. The understanding of teaching and training methodologies developed through an exchange program will add certain value to the existing courses offered by the institutions through collaboration. A CEP in media studies will help students understand, practice, and appreciate cultural ideas and differences between each other, deal with problems, and find out possible solutions through exchange of information (Mason, 1994). The knowledge and learning gained through an exchange program can be retooled and re-used by faculty and students in many (re)productive ways after returning from the host country. The faculty can incorporate these acquired knowledge and information in their teaching and curricula, whereas the students can share their experience with their peer group through blogs, e-mails, and other social networking sites. Needless to say, any evolved interaction and opening of communication provides for dialogue between different cultures which in turn lessens the fear, hate, and conflict with the 'foreign' (Coombe, Lillis, \& Commonwealth Standing Committee, 1989).
The youth in both developed and developing countries are growing up in a world where global processes place new demands on educational systems that are traditionally averse to change. People are noticing mediated technologies everywhere, and the virtual interactions are taking place over several digital communication interfaces. The communication business has ushered in a new age of consumer-designed content. This demands new approaches to media studies, that is a wider understanding of diverse theoretical and methodological approaches to study the changing media environments with its applied, professional, and pedagogical perspectives (Murray \& Ferri, 1992). A collaboration on both national and international level with media institutions can help departments and institutions of mass communication/media studies of State and Central Universities of India generate a critical mass of research in newer domains of media studies that will create an ambience in which new ideas, research, and scholarship will flourish and from which the leaders and innovators of tomorrow will emerge (Charles, 2006).

\subsection{Possible and Probable Framework for Conceptualization of CEPs}

While conceptualizing a framework, mindful consideration is required to design and develop technological literacy resources, networks, data storage capacities, multi-ethnic and multicultural inclusion and awareness, and the selection criteria of students and faculties for the exchange programs. The proposals for connect exchange programs should be designed in such a way that they are easily extendable for longer phases asking for financial support in realistic and feasible ways to strengthen the requirements of resources supporting each phase (Brodin, 2010). 
Currently there is a tectonic shift in the Indian media education system. In the globalized socio-economic world, the students are demanding a learning system at par with international standards. Universities and institutions have become crucial centers in equipping the newer generation for professional and personal development. The central universities established in 2009 have started with the goal of reaching the most advanced knowledge to a wide range of stakeholders.

The goal of Indian universities in this digital global world is to advance knowledge through innovative and creative teaching, research, and scholarship. The higher education system of the country is dedicated to preparing the youth to be ethical leaders for a diverse and globally competitive workplace.

A CEP in media studies needs a clear focus to foster mutual understanding of teaching, research, and service to facilitate educational reforms for both institutions that are eager to collaborate. The program needs an operational strategy to engage students and faculty of collaborating institutions in tasks involving global diversity (Delevett, 1997). The possibility should be to foster discussions relating to civil societies through international perspectives and sustain the efforts beyond the project timeline (Altbach, 2004).

The solutions for the pedagogical issues and concerns of media education in this country will only come from glocal (global + local) communication approaches. This approach is an understanding of the local cultural practice examined through intercultural exchange, and through reciprocal teaching, learning, and global application (Chen \& William, 2008). It is needless to assert that a new pedagogy is required to educate and prepare a skilled workforce for global media business.
Presently, there are many insurmountable challenges that prevent educational systems around the world from creating sustainable intercultural connections and exchanges that prepare students and teachers for evolved knowledge work. Most of the students in developing countries cannot afford to study in first world countries without the support of increasingly rare scholarships (Doyle, Gendall, Luanna, Hoek, Tait, McKenzie, \& Loorparg, 2009).

A connect exchange program will help students of different countries try on the others' cultural ideas for experience, and see problems and possible solutions through the others' viewpoint (Farah, 2001). The conventional study abroad model that is mostly in practice requires students and faculty to plan and prepare to shed all of their obligations and family responsibilities for at least three to four months. With this, much time on location and relocation is spent maintaining obligations at home and adjusting to cultural variations.

The new requirement is to design the connect exchange programs more as cultural tourism than academic rigor (Jenkins, 2006). The average transportation, educational, food, and lodging costs in any European country or United States is higher for the Indian student. Many of the practiced 'study abroad' models are simply unaffordable to most of the students and faculty. Then the program also lacks a clear estimation of how much learning from these study abroad programs can be retooled and re-used in productive ways once the student or faculty member returns from the host country.

The media educational institutions in this country need a framework for the study abroad model that embraces a philosophy of divergence, global practice, focused 
academic instruction that scaffolds extended intercultural professional relationships, and a model that could provide practical pedagogical approaches for workplace problem-solving (Lindsey, 2010).

\section{Timeframe}

A connect exchange program in media studies can range from three to four months, or from two to three years. It depends on how the two institutions are willing to collaborate and engage with the students and faculty in an enriching manner.

In a highly interactive connect exchange program the intercultural learning gets initiated with the access readily available for both the institutions. Today, content flows across multiple media platforms and is combining technological, industrial, cultural, and social changes. Every story gets told, and students and faculty as consumers need to be trained and oriented how to participate actively to be producers of mass content (Anderson, 2003). Instead of going for a study abroad experience with little knowledge about how an area works, it is better to use highly interactive tools such as live video, audio, and recorded feeds, an open-source customizable interactive course management system, and mobile devices to connect before the exchange, to converge in order to diverge.

In a CEP, timeframe for various activities is important. For example, a one-year exchange program is designed in four phases of three months each. Then, it is important to fix the timeframe for each phase and plan the activities for that phase. In the first phase, the students and faculty from both institutions may be required to have frequent interactions using video and audio technologies through a customized virtual learning environment. The projection of live Internet protocol cameras from both institutions, streaming to the connect exchange classroom and to mobile tablets and home computers, will acclimatize students and faculty to cultural differences. Some of the shared assignments can involve groups made up of students and faculty members from both institutions.

In the second phase, the students of both the institutions can travel to the places where the institutions are located to experience the culture of both countries. In this phase, there is ample scope to organize symposiums on multiethnic and multicultural themes and to engage the faculty and students in some community projects on concepts related to civil societies (Charles, 2006). These activities can also incorporate making small documentaries through film, audio, and text and they will have an opportunity to combine combinations of workplace observations with their academic course work, symposium learning, cultural excursions, and interpersonal experiences with the host family experiences in an electronic portfolio at the end of the exchange program (Miranda, 2013).

In the third phase, a mix of face-to-face and virtual exchange may take place. The effort here is to move effectively between the exchanges. Activities should be designed and implemented in such a way that the students and faculty of both institutions should closely observe and learn communication between multiple cultures with a critical and discerning eye, and should also learn to place this learning in different practical life situations by using natural media types and new media tools. Documentation of learning through the CEP should account for the fourth phase in which future course and emerging questions and tasks for further understanding shall be enumerated.

\subsection{The Implementation Framework (Activities to the Core)}


The citizens of the twenty first century must learn to perceive through minds of people from cultures other than their own. Several important trends of the late twentieth century like technology, development, globalization of the economy, widespread mass migrations, and the evolution of multiculturalism have transformed the world into a global village (Littman, 1997). In order to live meaningfully and productively in this world, individuals must evolve their intercultural communication competence.

In this view, a lot of core activities are required to conduct in tune with the resources available at both institutions collaborating together. Some of these activities could be similar to the engagements listed below:

1) Virtual discussion about the technological needs for interinstitutional collaboration.

2) A complete process to study syllabi, interact with faculty across many departments of both institutions, explore workplaces that could be useful for ethnographic study for students, and to examine available resources.

3) Designing and implementing a project work to avail opportunities to work together with a team of project assessors from outside partner universities/ institutions to develop a process for generating the formative, summative, and cumulative assessment reports.

4) To conduct symposiums/workshops at each collaborating institution for students and faculty over multi-ethnic and intercultural topics, a multicultural communication workshop for faculty development at each institution, and professional development for teaching with the aid of technology and assessment refreshers. Materials such as blog reflections, edited digital video, pictures, multimedia presentations, syllabi analysis, findings, etc. will be shared with faculty members at each institution in order to support each others' work. Participation of faculty and students from partner institutions can help build rapport and support and discover new ways to collaborate. It should also be an excellent opportunity for sharing and uncovering educational strategies crucial to the individual growth of the participants and also for the institutions.

5) Faculty and students visit for a prescribed duration to work with the host university. Faculty, students, administrators, media specialists, and technology administrators engage to discover similarities and variances in approaches to teaching and research between the countries of the two institutions/universities in collaboration.

6) The interactions which will be held during the exchange visit can be shared to strengthen methodological approaches and assessments measurements for intercultural findings between universities/institutions. The sharing of content could take place through blog exchanges and mediated video reflection.

7) Preparing reports for the funding agencies as most of the programs are financially supported by external agencies to analyze the connect exchange program in terms of technologies needed, logistics required, and to assess the co-curricular value from the students and faculty of both collaborating institutions and writing of grants to support the remaining phases 
of the program.

8) Writing for grants should be supported by a work plan including working together to refine the virtual learning environments, developing a database and backend video management process, and a procedural codec to purchase and secure the needed mobile and distance-learning equipment.

9) The ethnographic understanding of the intercultural workplace-learning experience of the students and faculty of both the institutions can help the institutions/universities to refine the existing degree/diploma program, and design and introduce new programs in media and cultural studies.

\subsection{Preparing and Proposing Budget}

Every and any CEP requires financial assistance. Thus, when planning for funding the following two categories should be considered: travel of the faculty and students of both institutions and educational aids/ technologies to support the work and exchange at both institutions. Assistance will be required for stipends, visa fee, local travel, within-country travel, international travel, lodging, meals, health insurance, purchase of technology, incidentals and accidentals, and other necessary items.

Finance in a CEP designed for media studies also requires the purchase of audiovideo equipments and a small portable production laboratory to combine the science of computers and linguistics-based audio learning software with the humanistic and scenariobased audio-visual tutorials. The equipments and production lab also help the students and faculty learn strategies for working with digital media and in virtual environments to sustain study abroad exchanges.
A cost-effective connect exchange program should be designed in such a way that it should not take away the work time of the faculty and students in the program. To do this, the program should augment realtime work environments with virtual learning environments and more technology, which is in keeping with the discipline of communication/ media studies specifically and globalization processes in general. Educational supplies and technology requests should be budgeted separately, as they are crucial components toward developing the infrastructure of exchange programs in media studies.

Another important component in any exchange program where huge expenditure is required is the inclusion of cultural excursions. A clear mention of when and where these excursions will take place must be part of the budget. The cultural excursions are important for both faculty and students of both institutions to interact in each other's sociocultural context. The excursions may include tours of workplace environments (Neff, 2001).

To make the budget more cost-effective, saving additional costs by travelling, eating, and lodging when and wherever possible in groups is useful. Educational materials and technologies required for teaching, research, and service work by the faculty can be pooled. Finding host families for the students of both countries can also help reduce the lodging cost.

Investment required in technology support and for educational materials like digital video camera, universal converter, memory sticks, mobile tablets, and cases are one time investments and will be the property of the host institutions once the program is over.

It is not advisable to include indirect costs in budget proposals because in this kind of program, the participant institutions have long-term commitments. People from 
both institutions will invest much of their time and energy into travelling, and taking away from time they would be dedicating to other work, including faculty and assessors. In order to maximize that time and minimize additional time spent, the best strategy is to make provisions for highly interactive and ubiquitous access to communication technologies. This fits nicely with the connectexchange study abroad program in that it saves cost by increasing virtual exchange to augment a decrease in face-to-face exchange (Ahamer, Kumpfmuller, \& Michaela, 2011). The money spent toward a one-time infrastructure technology cost makes much more sense than spending a lot more money on lodging, food, and local transportation costs for longer stays in the other country.

\subsection{Infrastructural Requirements}

The infrastructural requirement of a CEP is to create a room at partner institutions to have video and audio streaming and recording equipment, wireless microphones, and a video display and control unit. The purpose of these audio/video equipments is to record data to a computer SANS server. All data must be made available for live viewing, including promotional or observing purposes, but also remotely by students and faculty.

Faculty involved in the CEP should also need editing hardware and software to edit the content available at the SANS server in productive ways in order to sustain the exchange programme, using content in future curriculum and research and service projects.

A small portable media laboratory at the both the institutions with two mounted IP pantilt zoom cameras that are in colour can record sound and capable to be wired to a server to record faculty lecture video and to live stream both feeds. The laboratory can be a part of the exchange room itself. These video feeds are components of virtual learning environment that would help both participating institutions maximize interaction between students, faculty, and administrators. The audio and video can be digitally synchronized through the video cameras and the server can be attached to wireless microphones to make it available for the faculty and students of the exchange program. With this kind of infrastructure, camera feeds can be easily deployed through an application connected to the password-protected virtual learning environment. Many of the aforementioned technologies are central to any media education program. If the institutions already have a media production laboratory/studio, the feeds can be easily displayed on a television mounted in the connect-exchange room in order to foster live exchanges between students and faculty during meeting and interactive sessions. A system in duplication could also be made available to the offices of the authorities who are administering the program for further educational reform and pedagogical practice advice.

The advantage of a Storage Area Network Server (SANS) is that it will make all the storage devices available to all other servers on a LAN or WAN. It can be used to host live and recorded video and stream it for copying and editing for other purposes like enhanced video lectures. The servers are also needed for redundant backup and for speed and latency streaming speeds. These servers installed at the connect exchange rooms will enable live feeds and the storage of video for later viewing and editing. For example, a faculty member will enter the connect exchange room, push a button on the wall to begin recording to the SANS server, deliver his/her lecture and engage with the students, and before leaving push another button and the view recording will stop. The file is automatically converted into a variety of formats and enters into a 
database that includes the location, day, and time. The interface available at the partner institutions enables users to provide key terms for coding the video so that eventually users can search the video and jump to sections using key terms. The video will automatically copy to the SANS server in the partner institution as both a backup and to maximize speed and quality for downloading.

All the video components of the exchange program will be automatically stored in a database and archived. Training sessions are organized both physically and virtually at the partner institutions to train the faculty and the students to work with the equipment and make them familiar with the virtual teaching environment. The cameras and editing equipment can also be used at cultural excursions, conferences, workshops, and other events related to the exchange program. The communication technologies strategized for the exchange program will help the institutions deepen connections and ideas through integrating digital new media tools.

\section{The Assessment Plan}

In order to sustain a highly innovative and creative CEP, a thorough program assessment plan is required. The plan needs to be designed and executed in such a manner that it critically examines the extension of intercultural communication competence including new areas of research concerning multiple identities that individuals associate with. The project may evolve into an interconnected global society. The social and cultural identities of the media students of the two partner institutions located in different countries and the way the differences influence and affect each other and coexist with local influence is something that needs to be adequately addressed in the assessment plan of a connect program. Two assessors, one for each the partner institutions, will be required to understand the social and cultural environment of both places, institutions, and also the current landscape of higher education in both the countries.

The assessment plan will have monthly reviews and have a detailed assessment of financial statements, analysis of activities, and its objectivities through observation, faculties' and students' opinion and views, and corrective actionable recommendations. The assessment plan also reviews the goals and methods and pedagogies employed in the connect exchange program. Some commonly practiced methods are count, interview, observation, self-reporting, blogging, preand post-learning survey, artifact analysis, and regular interaction with the students and faculty participating in the program.

The assessment of each phase of the exchange program will help participating institutions maximize learning opportunities to bridge the pedagogical, methodological, technical, and linguistic barriers. The assessment plan also helps institutions develop a better understanding of ethical knowledge making and sharing in a global world. The assessment plan will work as a guiding-post to interpret social and cultural diversity in terms of ethnicities, races, genders, sexual orientations, castes, religions, geographic locations, and economic and political status. The outcomes of the assessment plan will be beneficial to the students and faculty participating in the exchange program to enable them to maximize application of their global learning in local communities, environments, and situations.

\subsection{Potential Advantage for Students and Faculty}

The innovative virtual learning environment in connect exchange program is a 
cost-effective way to interact with the students and faculty in their connect exchange rooms, and it affords the opportunity to seamlessly record video and share and edit it for future use. The approach synchronises values of new media with globalization and methods of communication with broadcasting and digital communication. The benefits coming along with the new communication technologies can be extended to every student, both inside and outside the classrooms, in more immediate and interactive ways.

Provision of cost-effective mobile handsets and tablets in the exchange program will definitely improve access to the virtual learning environment and online content for both students and faculty participating. Such mobile devices can also stream video over the server across multiple delivery platforms to further maximize interaction with others. The new information and communication technologies like laptops, notebooks, tablets, and smart phones are now a part of the curriculum of higher education in both developed and developing countries. These devices are now aggressively used to share video lectures, text and readings, share conversations and meetings, and used to interact in workplaces and the academy.

The need to pilot test and explore how this may work with the students and faculty of both institutions participating in the exchange program is needed. Spending time overseas is a very useful experience, but when one returns home, knowing how to continue to interact and communicate with others from the host countries is imperative to any exchange program (Peten, 2003). Using cost-effective tablet devices extensively to connect, followed by faculty and student visits and exchanges, and followed again by using the tablet devices for follow-ups can teach students and faculty about best practice strategies for interacting effectively from a distance. These interactions include ways to think about distance learning, collaborating on projects with international partners, researching through integrating others' ideas, etc. Orientation of the students and faculty to work with digital communication technologies will help them create and share content over multiple delivery platforms like portals, blogs, social networking sites, and protocol based web-broadcastings.

\subsection{The MHRD/UGC and the CEPS}

The National Innovation Council chaired by Sam Pitroda was set up by the Ministry of Human Resource Development (MHRD), Government of India to develop a national strategy on innovation in higher education with an Indian model in mind. The council has strongly suggested that CEPs will help institutions collaborate to design and develop dynamic curriculum by learning from each others' experiences and changing needs. Such interaction will help institutions encourage analytical and inquisitive attitudes of faculty members and students, and provide them an early exposure to research and entrepreneurship with an emphasis on co-curricular activities (University Grants Commission, 2009).

The MHRD has also signed cultural agreements with 118 countries. In the last two years, nearly about 75 cultural exchange programs were linked. Besides having an External Academic Relations Unit in the UNESCO division to handle bi-lateral relations, the MHRD has also established an Internal Co-operation Cell to coordinate the work related to the bilateral and international collaboration in the education sector. This cell has also been assigned the task to formulate, implement, and monitor the educational exchange programs between various countries with more attention to this kind of collaboration. 
A Joint Working Group is also established to implement and monitor CEPs and to look after initiatives like exchange of scholars, students, and researchers, sharing of information and publications, organizing seminars, workshops and conferences together, developing institutional linkages, and to look after the financial part of these exchange programs.

Initiatives like India-UK Higher Education Leadership Development Programme, Joint Declaration on Multilingualism between India and European Union, Obama-Singh 21st Century Knowledge Initiative between India and United States of America are encouraging the policy makers in higher education to conceptualize collaborations with universities outside country through faculty exchanges, research, and innovation and to further the possibilities to implement technology-enabled education strategies to facilitate exchange programs between Indian universities and universities abroad (Davies, 1997). The Fulbright-Nehru program is helping both Indian institutions and institutions of learning in the United States to exchange nearly 300 students and scholars every year.

In 2012, the MHRD has finalized a framework for establishing community colleges in India. A high-level Indian delegation visited the United States to study the community college system and collaborated with the American Association of Community Colleges to conceptualize and develop infrastructure and capacity to establish community colleges in India. The University Grants Commission also framed new regulations and guidelines for twinning arrangements between Indian and foreign educational institutions (Hasan \& Nussbaum, 2012). In this connection, the 'Connect India Programme' has been launched in June 2012 that facilitates 200 students from the United States to study a semester at various educational institutions of India. The study has been integrated with other activities like an introduction to Indian culture and economy, service-learning with corporate entities, and interaction with political representatives. Other initiatives like India-Support for Teacher Education Programme, Passport to India, and Education USA promotes student exchange in the form of small internships, service-learning, study a module to understand pedagogy and assessment techniques, pursue individual projects, and conduct short-term research to further economic, academic, and social ties with foreign universities and institutions of repute.

\section{Conclusion}

A CEP is an innovative platform for the young learners around the world to participate in various higher educational activities to learn and practice innovations and expand their cultural understanding of global working places. A number of initiatives in the form of exchange programs conceptualized and implemented by MHRD and UGC of India were providing interactive opportunities for the students and faculty of higher educational institutions of the country to gain expertise to practice new pedagogy and teaching methodologies in many disciplines of social sciences and humanities including media studies.

A well thought and organized CEP in Media Studies not only contributes to the paradigm of the discipline, but simultaneously in many other disciplines. Any intercultural exchange between adults evolve to a more harmonious and cogent world to live, when these exchanges become a part of an academic endeavour these can be a panacea for the evils that plague human society ranging from discriminatory social system to hierarchal knowledge categorization. 


\section{References}

Agarwal, P. (2009). Indian higher education: Envisioning the future. New Delhi: SAGE.

Ahamer, G., Kumpfmuller, K.A., \& Michaela, H. (2011). Web-based exchange of views enhances "Global Studies." Campus-Wide Information Systems, 28(1), 16-40.

Allen, W. R., Bonous-Hammarth, M., \& Teranishi, R. T. (2006). Higher education in a global society: Achieving diversity, equity and excellence. Amsterdam: Elsevier JAI.

Altbach, G. P. (2004). Globalization and the university: Myths and realities in an unequal world. Tertiary Education and Management, 10(1), 3-25.

Anderson, D. (2003). Prosumer approaches to new media composition: Consumption and production in continuum. Kairos: A Journal of Rhetoric, Technology, and Pedagogy, 8(1), 18-22.

Bhaduri, S. (Ed.). (2008). Negotiating glocalization: Views from language, literature and cultural studies. New Delhi: Anthem Press.

Brodin, J. (2010). Education for global competencies: An EU-Canada exchange programme in higher education and training. Journal of Studies in International Education, 14(5), 569-584.

Celly, A. (2008). Towards a new paradigm in higher education. Delhi: Kalpaz Publications.

Charles, D. (2006). Universities as key knowledge infrastructures in regional innovation systems. Innovation: The European Journal of Social Science Research, 19(1), 117-130.

Chen, G.M. \& William J.S. (2008). Intercultural communication competence. In Molefi, K., Asante, Y.M. \& Jing, Y. (Eds.), The global intercultural communication reader (pp. 215227). New York: Routledge.

Coverdale, J.T. (2013). Transnational higher education in Asian context. Hampshire: Palgrave Macmillan.

Coombe, C., Lillis, K. M., Commonwealth Standing Committee on Student Mobility and Higher Education Co-operation, \& Commonwealth Secretariat. (1989). International development programmes in higher education: A report to the commonwealth standing committee on student mobility and higher education co-operation. London: Commonwealth Secretariat. Retrieved from http://lst-iiep.iiepunesco.org/cgi-bin/wwwi32.exe/[in=epidoc1. in] $/ ?$ t2000 $=003662 /(100)$

Dahlgren, P. (2009). Media and political engagement: Citizens, communication, and democracy. Cambridge: Cambridge University Press.

Davies, H. (1997). The EU higher education exchange and mobility programmes. London: University of North London.

Davies, M., Devlin, M., \& Tight, M. (2010). Interdisciplinary higher Education: perspectives and practicalities. Bradford: Emerald Group Publishing.

Delevett, P. (1997). Exchange can help students explore career possibilities. New Orleans City Business, 18(4), 13.

Downing, J. (2004). The SAGE handbook of media studies. Thousand Oaks, Calif: Sage Publications.

Doyle, S., Gendall, P., Luanna, M.H., Hoek, J., Tait, C., McKenzie, L., \& Loorparg, A. (2009). An investigation of factors associated with student participation in study abroad. Journal of Studies in International Education, 14(1), 471-490.

Farah, S. (2001). Their home is a revolving door for the world. Christian Science Monitor, 93(89), 16.

Ghosh, S. (2008). Modern trends in journalism and mass communication. New Delhi: Adhyayan Publishers \& Distributors.

Hasan, Z., \& Nussbaum, M. C. (2012). Equalizing access: affirmative action in higher education in India, United States, and South Africa. New Delhi: Oxford University Press.

Haythornthwaite, C., \& Barry, W. (1998). Work, 
friendship, and media use for information exchange in a networked organization. Journal of the American Society for Information Science, 49(12), 1101-1114.

Jenkins, H. (2006). Convergence culture: Where old and new media collide. New York: New York University Press.

Lavender, T., Tufte, B., \& Lemish, D. (2003). Global trends in media education: Policies and practices. Cresskill, N.J: Hampton Press.

Levy, M. R., \& Gurevitch, M. (1994). Defining media studies: Reflections on the future of the field. New York: Oxford University Press.

Lindsey, U. (2010, December 5). Online programmes connects students across cultural and national borders. The Chronicle of Higher Education, 1. Retrieved from http:// chronicle.com/article/A-Virtual-ExchangeProgram/125601/

Littman, M. (1997). Training the global village's future leaders. Crain's Chicago Business, 20(9), 32.

Malamud, S. (1993). Making your way abroad. Career World, 21(8), 15.

Maslog, C. C., Press Foundation of Asia \& Communication Assistance Foundation. (1990). Communication education in Asia: Status and trends in India, Indonesia, Malaysia, Nepal, Philippines and Thailand. Manila, Philippines: Press Foundation of Asia.

Mason, R. (1994). Using communications media in open and flexible learning. London: Taylor $\&$ Francis.

Messer, D., \& Wolter, S.C. (2005). Are student exchange programs worth It? Stefan, C.W. Discussion Paper Series No. IZA DP No. 1656. Bonn, Germany: Institute for the Study of Labor (IZA). Retrieved from http://ftp.iza. org/dp1656.pdf

Miranda, M. (2013). Getting the moose out of international exchanges. ATA News, 47(11), 1.

Murray, M. D., \& Ferri, A. J. (1992). Teaching mass communication: A guide to better instruction. New York: Praeger.
Neff, R. A. (2001). Discovering heritage and more by studying abroad. Black Issues in Higher Education, 18(12), 32.

Peten, C. (2003). Programs gives students a chance to work and see the country. Saskatchewan, 7(4), 17.

University Grants Commission. (2009). Annual report for the year 2009-10. Retrieved from http://www.ugc.ac.in

Tejerina, F. (2011). The university: An illustrated history. Madrid: Turner.

\section{Contact the Author}

\section{Pradeep Nair}

Associate Professor and Head, Department of Mass Communication \& Electronic Media,Central University of Himachal Pradesh, Dharamshala, India

Email: nairdevcom@yahoo.co.in

\section{Navneet Sharma}

Assistant Professor, Department of Teacher Education, Central University of Himachal Pradesh, Dharamshala, India 